\title{
Risk factors associated with conversion of an Ommaya reservoir to a permanent cerebrospinal fluid shunt in preterm posthemorrhagic hydrocephalus
}

\author{
Alexis Palpan Flores, MD, ${ }^{1}$ Javier Saceda Gutiérrez, PhD, MD, ${ }^{1}$ Juan Raúl Brin Reyes, MD, ${ }^{2}$ \\ Jaime Sierra Tamayo, MD, ${ }^{3}$ and Fernando Carceller Benito, PhD, MD1
}

'Department of Pediatric Neurosurgery, La Paz University Hospital, Madrid, Spain; '2Department of Pediatric Neurosurgery, Omar Torrijos Herrera Hospital, Panama City, Panama; and 'Department of Neurosurgery, San Jose Hospital, Bogota, Colombia

\begin{abstract}
OBJECTIVE A considerable percentage of preterm infants with posthemorrhagic hydrocephalus initially managed with an Ommaya reservoir require a permanent CSF shunt. The objective of the study was to analyze possible risk factors associated with the need for converting an Ommaya reservoir to a permanent shunt.

METHODS The authors retrospectively reviewed the clinical records of premature infants weighing $1500 \mathrm{~g}$ or less with posthemorrhagic hydrocephalus (Papile grades III and IV) managed with an Ommaya reservoir at their institution between 2002 and 2017.
\end{abstract}

RESULTS Forty-six patients received an Ommaya reservoir. Five patients (10.9\%) were excluded due to intraventricular infection during management with an Ommaya reservoir. Average gestational age and weight for the remaining 41 patients was $27 \pm 1.8$ weeks and $987 \pm 209$ grams, respectively. Thirty patients required a permanent shunt and 11 patients did not require a permanent shunt. The conversion rate from an Ommaya reservoir to a permanent shunt was $76.1 \%$. Symptomatic persistent ductus arteriosus (PDA) was more frequent in the nonpermanent shunt group than in the shunt group ( $88.9 \%$ vs $50 \%, p=0.04$ ). The need for extraction of more than $10 \mathrm{ml} / \mathrm{kg}$ per day of CSF through the Ommaya reservoir was lower in the nonpermanent shunt group than in the shunt group $(9.1 \%$ vs $51.7 \%, p=0.015)$. CSF lactate was lower in the nonpermanent group than in the shunt group (mean $2.48 \mathrm{mg} / \mathrm{dl}$ vs $3.19 \mathrm{mg} / \mathrm{dl} ; \mathrm{p}=0.004$ ). A cutoff value of $\geq 2.8 \mathrm{mg} / \mathrm{dl}$ CSF lactate predicted the need for a permanent shunt with sensitivity and specificity of $82.4 \%$ and $80 \%$, respectively. There were no significant differences in gestational age, sex, weight, Papile grade, ventricular index, or other biochemical markers. After the multivariate analysis, only CSF lactate $\geq 2.8 \mathrm{mg} / \mathrm{dl}$ was associated with a higher conversion rate to a permanent shunt.

CONCLUSIONS This study showed that a high level of CSF lactate, absence of symptomatic PDA, and a higher CSF extraction requirement were associated with a higher likelihood of implanting a permanent CSF shunt. The authors believe these findings should be considered in future studies.

https://thejns.org/doi/abs/10.3171/2019.11.PEDS19320

KEYWORDS posthemorrhagic hydrocephalus; permanent shunt; prematurity; intraventricular hemorrhage; Ommaya reservoir; ventricular access device

$\mathrm{G}$ ERMINAL matrix hemorrhage (GMH) and intraventricular hemorrhage (IVH) occur in approximately $15 \%-20 \%$ of infants weighing less than 1500 $\mathrm{g}$ and in $50 \%$ of those weighing less than $750 \mathrm{~g} .{ }^{11}$ IVH was classified by Papile according to the extent of hemorrhage and severity of hydrocephalus, and this classification has a direct relationship with cognitive deficits, disability, and mortality. ${ }^{17,19,21,22}$ Between $25 \%$ and $50 \%$ of grade III and IV hemorrhages develop progressive hydrocephalus, which requires a temporary device for shunting CSF, ${ }^{16}$ because a definitive CSF shunt is not justified in infants under $1500 \mathrm{~g}$ due to a high risk of complications such as intestinal perforation, shunt infection, and high rates of shunt revision. ${ }^{7,27,29}$

ABBREVIATIONS $\mathrm{Cl}=$ confidence interval; $\mathrm{GMH}=$ germinal matrix hemorrhage; $\mathrm{IVH}=$ intraventricular hemorrhage; $\mathrm{PDA}=$ persistent ductus arteriosus; $\mathrm{OR}=$ odds ratio; $\mathrm{RBC}=$ red blood cell; ROC = receiver operating characteristic.

SUBMITTED May 31, 2019. ACCEPTED November 11, 2019.

INCLUDE WHEN CITING Published online January 17, 2020; DOI: 10.3171/2019.11.PEDS19320. 


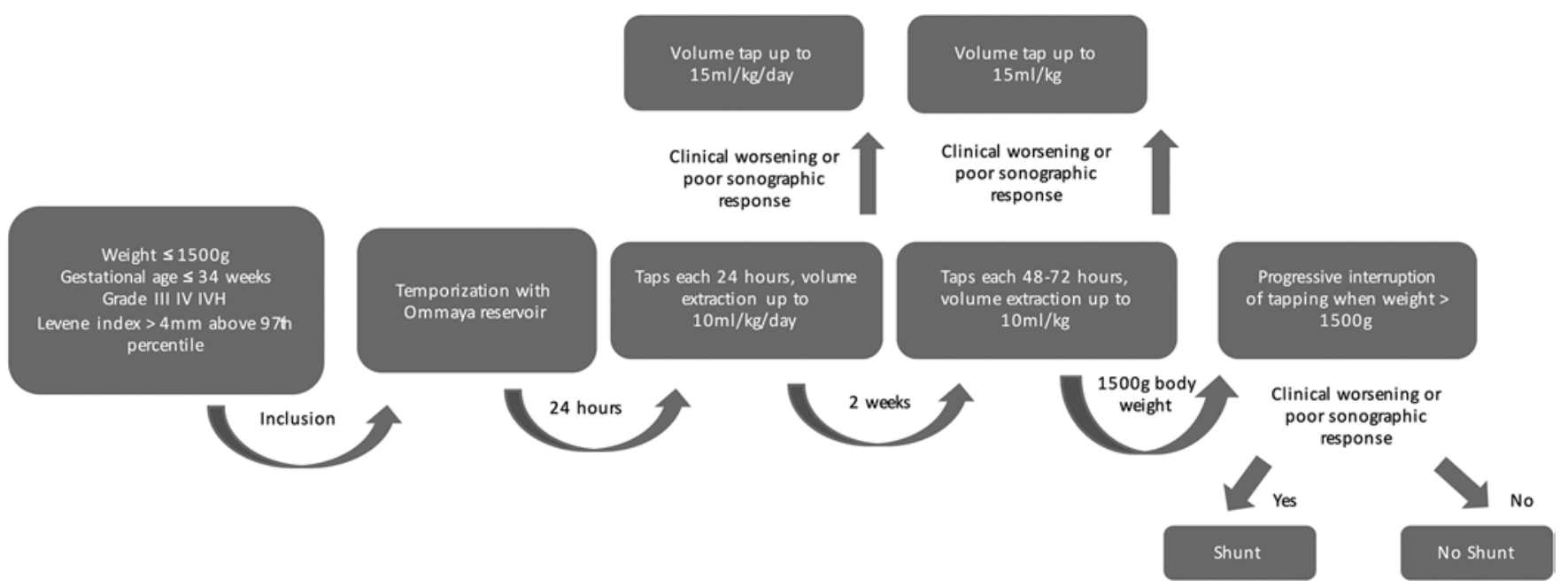

FIG. 1. Management algorithm after implantation of the Ommaya reservoir.

Several alternatives have been studied as temporizing measures for hydrocephalus. Early lumbar taps, repeated ventricular taps, and external ventricular drains are associated with high rates of shunt infection and are less effective in reducing the need for permanent shunts than ventricular reservoirs and ventriculosubgaleal shunting. ${ }^{2,4,18}$ There is no evidence of superiority between the latter two techniques, with both presenting shunt conversion rates of 65\%-95\% among different studies. . $^{14,30,31}$

Undergoing a permanent shunt placement has longterm implications. Some studies show a greater degree of neurological abnormalities, a smaller cranial circumference, and an important rate of shunt revision. ${ }^{1,4,7,30} \mathrm{~A}$ careful selection of those patients who will require a permanent shunt can lead to an earlier shunt implantation and avoid unnecessary taps that could be associated with complications. ${ }^{32,34}$

The main objective of this study is to analyze clinical, sonographic, and biochemical factors that might predict the need for a permanent shunt in patients who previously underwent placement of a ventricular reservoir as a temporization measure. We also analyzed reservoir-associated complications and risk factors associated with shunt revision during the first year in the same cohort of patients.

\section{Methods \\ Study Population}

We performed a retrospective observational study of all patients born between 2002 and 2017 in La Paz University Hospital in Madrid, Spain. Inclusion criteria were as follows: 1) gestational age $\leq 34$ weeks, 2) infant weight $\leq$ $1500 \mathrm{~g}, 3)$ presence of IVH classified as Papile grade III or IV, 22 4) progressive hydrocephalus with a Levene frontal index $>4 \mathrm{~mm}$ above the 97th percentile, 5) placement of an Ommaya reservoir, and 6) absence of infectious complications associated with the Ommaya reservoir.

During the study period, 59 patients underwent placement of an Ommaya reservoir. Eleven were excluded due to weight $>1500 \mathrm{~g}, 2$ died during the hospitalization due to other comorbidities, and 5 patients developed Ommaya reservoir-associated ventriculitis. The total study group consisted of 41 patients, 30 of whom required either permanent ventriculoperitoneal or ventriculoatrial shunting (shunt group) and 11 who did not require a permanent shunt (nonpermanent shunt group).

\section{Variable Measurement}

Demographic and clinical variables were measured and analyzed, as well as the rate of permanent shunt placement, shunt infection, and need for shunt revision during the first year. All preterm infants were evaluated with transcranial sonography before and after Ommaya reservoir implantation and changes in ventricular index after Ommaya reservoir taps were recorded. The neonatology protocol of our institution is as follows. Taps begin at 24 hours after implantation of the Ommaya reservoir with an extraction volume of $10 \mathrm{ml} / \mathrm{kg}$ of CSF every 24 hours for 2 weeks, unless clinical worsening or poor sonographic response occurs, in which case $15 \mathrm{ml} / \mathrm{kg}$ is extracted. We defined clinical worsening as a bulging fontanelle, bradycardia, or arterial hypertension, and poor sonographic response as a ventricular index greater than the preoperative value. After 2 weeks, $10 \mathrm{ml} / \mathrm{kg}$ is extracted every $48-72$ hours, unless clinical worsening or poor sonographic response occurs, in which case $15 \mathrm{ml} / \mathrm{kg}$ every 48 hours is extracted until the patient reaches $1500 \mathrm{~g}$ of body weight. After reaching $1500 \mathrm{~g}$, the extractions are gradually stopped within 2-3 weeks. If the patient shows clinical or sonographic worsening, a ventriculoperitoneal shunt is implanted (ventriculoatrial shunt if necrotizing enterocolitis has occurred or peritoneum is not available; Fig. 1) Some cases underwent a lumbar tap as a temporizing measure before placement of an Ommaya reservoir.

Measured variables in CSF were total proteins (mg/ $\mathrm{dl})$, glucose $(\mathrm{mg} / \mathrm{dl})$, lactate $(\mathrm{mg} / \mathrm{dl})$, white blood cells (cell count $/ \mathrm{mm}^{3}$ ), and red blood cells (RBCs). Because quantitative $\mathrm{RBC}$ analysis is not routinely available in our center, RBCs were measured qualitatively as follows: $0=$ 
TABLE 1. Demographic and clinical variables

\begin{tabular}{|c|c|c|c|}
\hline \multirow[b]{2}{*}{ Variable } & \multicolumn{2}{|c|}{ Shunt Group } & \multirow[b]{2}{*}{ p Value } \\
\hline & Nonpermanent & Permanent & \\
\hline No. of patients & 11 & 30 & \\
\hline Female sex, $\%$ & 54.5 & 50 & 0.53 \\
\hline Gestational age at birth, wks & $26 \pm 0.6$ & $27 \pm 0.22$ & 0.76 \\
\hline Gestational age, wks* & $30.79 \pm 1.8$ & $30.49 \pm 0.29$ & 0.61 \\
\hline Unadjusted age, days* & $22 \pm 5.5$ & $23 \pm 1.1$ & 0.47 \\
\hline Birth weight, $g$ & $991.1 \pm 89$ & $986 \pm 31$ & 0.84 \\
\hline Birth weight percentile & $69 \pm 7$ & $72.2 \pm 4.1$ & 0.74 \\
\hline Ventricular (Levene) index, $\mathrm{mm}^{*}$ & $18.57 \pm 0.9$ & $18.5 \pm 0.5$ & 0.76 \\
\hline Millimeters over the 97 th percentile of Levene index & $8.31 \pm 0.84$ & $8.27 \pm 0.6$ & 0.96 \\
\hline GMH grade, $\% *$ & & & 0.29 \\
\hline Papile grade III & 36.4 & 60 & \\
\hline Papile grade IV & 63.6 & 40 & \\
\hline Patients w/ lumbar taps, n (\%) & $4(36.4)$ & $15(50)$ & 0.49 \\
\hline
\end{tabular}

no RBCs, 1 = isolated RBCs, 2 = abundant RBCs, and $3=$ hematic CSF. All variables were registered at Ommaya reservoir implantation, on each Ommaya reservoir tap, and at the moment of permanent shunt implantation. The decision to place a permanent shunt was made if the patient weighed more than $1500 \mathrm{~g}$, had clinical stability, and had a poor response to Ommaya reservoir tapping or a ventricular index increase when Ommaya reservoir tapping was stopped. For the purposes of analysis, mean values of CSF variables during the use of the Ommaya reservoir were calculated and used.

Symptomatic persistent ductus arteriosus (PDA) was considered to be present in those infants with clinical criteria such as a characteristic heart murmur, hyperdynamic precordial impulse, tachycardia, bounding pulses, or worsening respiratory status in addition to echocardiographic criteria..$^{10}$ All these infants were treated surgically.

\section{Statistical Analysis}

Univariate results were expressed as counts and percentages for categorical variables, and as means and standard deviations for continuous variables. The Fisher exact test was used for bivariate analyses for categorical variables, and the Wilcoxon rank-sum test for continuous variables. The log-rank test was used to compare time until implantation of the permanent shunt. Receiver operating characteristic (ROC) curve analysis was performed to summarize the trade-off between sensitivity and specificity of different thresholds of CSF lactate and we chose the cutoff that offered the best percentage of correct classification; $p$ values were reported for all of these analyses. Multivariate logistic regression was constructed to predict conversion to a permanent shunt by using significant bivariate factors as well as the variables sex and gestational age. Results from the final model were reported as $\mathrm{p}$ values and adjusted odds ratios (ORs) with 95\% confidence intervals (CIs). The analysis was conducted using Micro- soft Excel 2016 and the statistical package Stata (version 13, StataCorp LLC).

\section{Results}

Thirty patients (73.2\%) underwent placement of a permanent shunt. The median gestational age was $27.02 \pm$ 1.81 (range 24-32 weeks), and the mean birth weight was $987.4 \pm 208.8 \mathrm{~g}$ (range 535-1500 g). Two patients underwent ventriculoatrial shunting due to necrotizing enterocolitis and unviable peritoneum; the rest underwent ventriculoperitoneal shunting. Mean gestational age, sex, weight at birth, Levene index, Papile grade, use of lumbar taps, and age until placement of an Ommaya reservoir are displayed for both groups in Table 1. There were no significant differences in any of the demographic or clinical variables between the groups. Of note, there was a higher proportion of patients with grade IV hemorrhage in the nonpermanent shunt group, but this difference did not reach statistical significance. Two patients (4.9\%) suffered wound dehiscence during the use of the Ommaya reservoir.

Of all registered comorbidities, symptomatic PDA was more frequent in patients in the nonpermanent shunt group $(88.9 \%, 8 / 9)$ than in the permanent shunt group $(50 \%, 15 / 30)$, with this difference being statistically significant ( $p=0.041$, Fig. 2). Sepsis was more frequent in the shunt group (63.3\%) than in the nonpermanent shunt group $(33 \%, p=0.142)$; necrotizing enterocolitis was similar in both groups, $11 \%$ in the nonpermanent shunt group and $10 \%$ in the shunt group $(\mathrm{p}=0.92)$.

During the use of an Ommaya reservoir, it is noteworthy that poor sonographic response after the first few taps showed a significant trend toward placement of a permanent shunt, but this finding was neither universal in the permanent shunt group nor did it guarantee the need for permanent shunt placement. The requirement to extract more than $10 \mathrm{ml} / \mathrm{kg}$ of CSF and the presence of elevated 


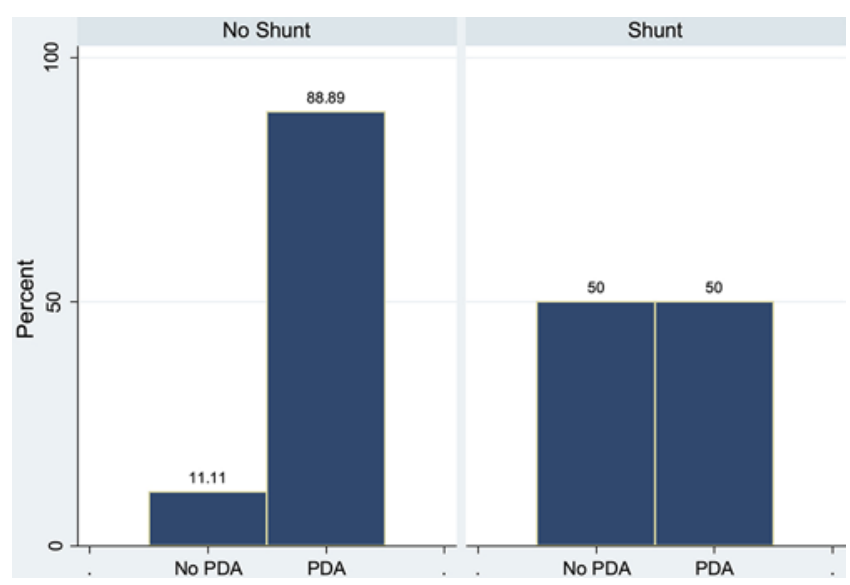

FIG. 2. Bar graph showing symptomatic PDA in each group and need for a permanent shunt. Figure is available in color online only.

CSF lactate concentrations were significantly associated with the need for a permanent shunt in our cohort. Both total protein content and white blood cell count were higher in the permanent shunt group, although these differences were not significant. The qualitative content of RBCs was also similar in both groups. Both groups used the Ommaya reservoir for approximately 30 days, although the standard deviation for the nonpermanent shunt group was much higher; regardless, there was no significant difference between groups in this measurement (Table 2).

CSF lactate was lower in the nonpermanent shunt group than in the permanent shunt group (mean $2.48 \mathrm{mg}$ / dl vs $3.19 \mathrm{mg} / \mathrm{dl}$, p = 0.004; Fig. 3). Cutoff values for CSF biochemical variables were explored through the use of ROC curves (Fig. 4). CSF lactate showed the largest area under the curve, and when using a cutoff value of $2.8 \mathrm{mg} /$ dl we obtained a sensitivity of $82.4 \%$, specificity of $80 \%$, and positive likelihood ratio of 4.1. Other CSF markers did not result in significant values. After multivariate logistic regression analysis in which we included demographic variables such as sex and gestational age, poor sonographic response, and extraction requirement more than $10 \mathrm{ml} /$

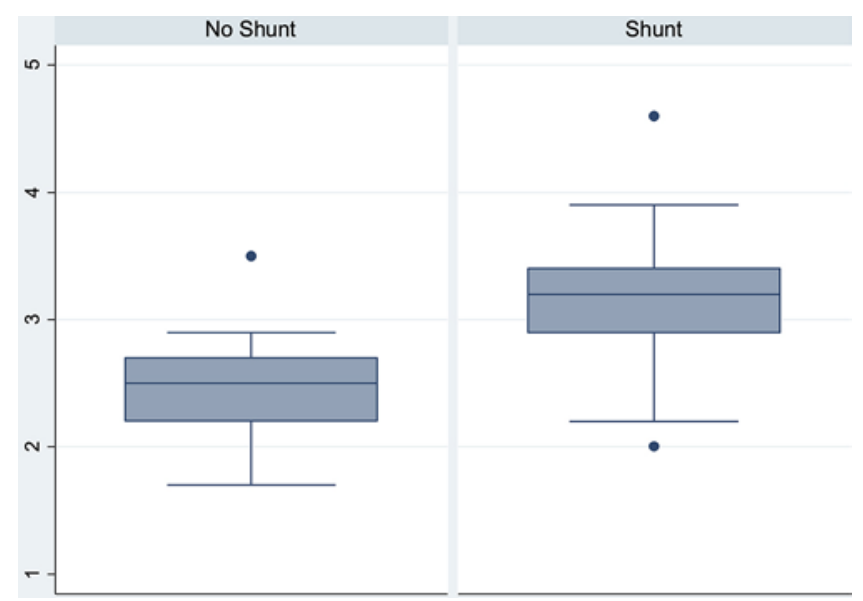

FIG. 3. Box plot for lactate levels in each group. The lines on the bars represent the 25 th, the median, and the 75 th percentile. The dots represent the most extreme values of the distribution (outliers). Figure is available in color online only.

$\mathrm{kg}$ of CSF, the only factor that remained independently associated with permanent shunting was a lactate measurement $\geq 2.8 \mathrm{mg} / \mathrm{dl}$ (unadjusted OR 10.7, 95\% CI 1.56-72.6, $\mathrm{p}=0.016$; adjusted OR $15.5,95 \%$ CI 1.06-225, $\mathrm{p}=0.045$ ). We did not include symptomatic PDA because the small sample size made the model unstable (Table 3).

Finally, possible risk factors for shunt revision in the 30 patients in the permanent shunt group were studied. Thirteen patients underwent revision during the first year after placement of a permanent shunt (43.3\%). There were no significant differences between patients who underwent revision and those who did not with regards to CSF biomarkers or time of Ommaya reservoir use (Table 4). Two patients who underwent revision had developed shunt infection.

\section{Discussion}

We present this retrospective report that investigated factors that can affect the rate of conversion to a permanent shunt. Most studies have focused on the rate of

TABLE 2. Variables during the use of an Ommaya reservoir

\begin{tabular}{lccc}
\hline \multicolumn{1}{c}{ Variable } & NPS $(\mathrm{n}=11)$ & PS $(\mathrm{n}=30)$ & $\mathrm{p}$ Value \\
\hline Poor sonographic response to $1 \mathrm{st}$ taps, $\mathrm{n}(\%)$ & $4(36.4)$ & $21(70)$ & 0.056 \\
\hline CSF extraction requirements $>10 \mathrm{ml} / \mathrm{kg}$ each day & $1(9.09 \%)$ & $15 / 29(51.7)$ & $\mathbf{0 . 0 1 5}$ \\
\hline Glucose $(\mathrm{mg} / \mathrm{dl})$ & $22.3 \pm 2.7$ & $16.13 \pm 1.6$ & 0.064 \\
\hline Protein $(\mathrm{mg} / \mathrm{dl})$ & $176.5 \pm 19.7$ & $230.1 \pm 43$ & 0.49 \\
\hline Lactate $(\mathrm{mg} / \mathrm{dl})$ & $2.48 \pm 0.1$ & $3.19 \pm 0.14$ & 0.004 \\
\hline RBC category $>2, \mathrm{n}(\%)^{*}$ & $6(54.5)$ & $14 / 29(48.3)$ & 0.50 \\
\hline White blood cells per $\mu \mathrm{l}$ & $7.5 \pm 2.6$ & $27.4 \pm 10.1$ & 0.15 \\
\hline Days of Ommaya reservoir use & $30 \pm 9.9$ & $32 \pm 1.5$ & 0.52 \\
\hline
\end{tabular}

NPS = nonpermanent shunt; $P S=$ permanent shunt.

All data given as mean $\pm S D$ unless otherwise indicated. Boldface type indicates statistical significance.

${ }^{*}$ RBC categories: $0=$ none, 1 = isolated, $2=$ abundant, $3=$ overly hematic CSF. 


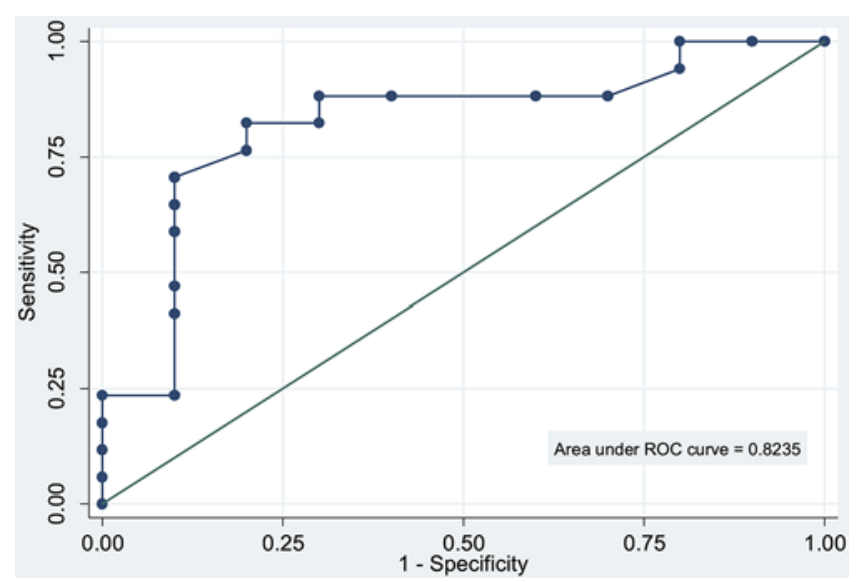

FIG. 4. ROC curve for CSF lactate. Figure is available in color online only.

conversion to a permanent shunt comparing different temporizing measures.,12 Few studies have described other variables associated with the conversion rate. In 1 multicentric study, clinical variables such as bradycardia, apnea, splayed sutures, frontal and occipital ratio, clot density, and clot location were analyzed, finding only the full bulging fontanel and larger ventricular size as factors associated with conversion to a permanent shunt. ${ }^{25}$

Optimal management of premature posthemorrhagic hydrocephalus is still under debate, with one of the fundamental goals of management being to reduce the need for permanent shunting. In our study we found a rate of conversion to a permanent shunt of $76.1 \%$ with the use of an Ommaya reservoir including cases of ventriculitis, similar to other series that use different transient ventricular CSF diversion devices. ${ }^{14,30,31}$

Because clinical and radiological criteria for implantation of a temporary shunt are not uniform between most series, it is possible that time to placement of an Ommaya reservoir is one of the variables related to placement of a permanent shunt. However, in our series there was no difference in the time to Ommaya reservoir placement, with a mean of 22 days in both groups. Other studies have reported mean times to insertion of an Ommaya reservoir between 28 and 39 days, with similar permanent shunt placement rates. ${ }^{30,31}$
TABLE 4. Risk factors for shunt revision during the first year after permanent shunt placement

\begin{tabular}{|c|c|c|c|}
\hline \multirow[b]{2}{*}{ Risk Factor } & \multicolumn{2}{|c|}{ Shunt Revision } & \multirow[b]{2}{*}{ p Value } \\
\hline & None & $\geq 1$ & \\
\hline No. of patients (\%) & $17(56.7)$ & $13(43.3)$ & \\
\hline Weight $(\mathrm{g})^{*}$ & $2093.6 \pm 141$ & $2306 \pm 226$ & 0.23 \\
\hline Protein $(\mathrm{mg} / \mathrm{dl})^{*}$ & $204.9 \pm 75.5$ & $184.8 \pm 36.6$ & 0.30 \\
\hline Glucose $(\mathrm{mg} / \mathrm{dl})^{*}$ & $20.5 \pm 2.2$ & $23.6 \pm 2.7$ & 0.29 \\
\hline Lactate $(\mathrm{mg} / \mathrm{dl})^{*}$ & $2.6 \pm 0.2$ & $2.55 \pm 0.13$ & 0.87 \\
\hline RBC category, $n(\%)^{*}$ & & & 0.63 \\
\hline No RBC & $3(60)$ & $2(40)$ & \\
\hline Isolated RBC & $6(37.5)$ & $10(62.5)$ & \\
\hline Abundant RBC & $3(60)$ & $2(40)$ & \\
\hline Hematic CSF & None & None & \\
\hline White blood cells per $\left.\mu\right|^{*}$ & $15.2 \pm 5.3$ & $6.4 \pm 2.3$ & 0.22 \\
\hline $\begin{array}{l}\text { Days of Ommaya reser- } \\
\quad \text { voir use }\end{array}$ & $32 \pm 2.05$ & $35 \pm 3.5$ & 0.33 \\
\hline
\end{tabular}

All data given as mean \pm SD unless otherwise indicated.

* At the time of permanent shunt implantation.

Of the main comorbidities associated with prematurity, we observed that symptomatic PDA was more frequent in the group that did not require placement of a permanent shunt, possibly because the resulting inadequate venous return may exacerbate an already deficient CSF absorption; however, because this condition is usually transient, closure of the PDA restores adequate venous hemodynamics, resulting in an improvement of CSF reabsorption.

All cases required multiple reservoir taps after placement of an Ommaya reservoir. Higher volume extraction requirements $\left(>10 \mathrm{ml} / \mathrm{kg}\right.$ of CSF per day) ${ }^{33}$ result in a higher probability of permanent shunt implantation, as well as poorer sonographic response to Ommaya reservoir taps, which appear to indicate a poorer physiological absorption capacity of CSF. Because the rate of Ommaya reservoir infection can be associated with Ommaya reservoir tap frequency, we opted in our series to increase the volume over the frequency of Ommaya reservoir taps.

Of the usual biochemical parameters measured in CSF, total glucose, protein, RBCs, and white blood cells were not associated with a higher likelihood of permanent shunt

TABLE 3. Multivariate logistic regression analysis for prediction to a permanent shunt

\begin{tabular}{lcccc}
\hline \multicolumn{1}{c}{ Predictor } & Unadjusted OR $(95 \% \mathrm{Cl})$ & $\mathrm{p}$ Value & Adjusted OR* $(95 \% \mathrm{Cl})$ & $\mathrm{p}$ Value \\
\hline Sex & $1.2(0.30-4.79)$ & 0.797 & $1.67(0.16-17.5)$ & 0.668 \\
\hline Gestational age & $1.1(0.68-1.48)$ & 0.051 & $1.36(0.72-2.66)$ & 0.358 \\
\hline Lactate $\geq 2.8 \mathrm{mg} / \mathrm{dl}$ & $10.65(1.56-72.6)$ & 0.016 & $15.5(1.06-225)$ & 0.045 \\
\hline $\begin{array}{l}\text { Requirement of extraction } \\
>10 \mathrm{ml} / \mathrm{kg}\end{array}$ & $10.71(1.21-94.8)$ & 0.033 & $33.1(0.51-209)$ & 0.099 \\
\hline $\begin{array}{l}\text { Poor sonographic response } \\
\text { Symptomatic PDA }\end{array}$ & $4.08(0.95-17.5)$ & 0.058 & $0.82(0.06-10.3)$ & 0.879 \\
\hline
\end{tabular}

* Model $p$ value $=0.018$, pseudo $R^{2}=0.394$. 
placement. Total protein content has been previously correlated with obstruction of the permanent shunt system, ${ }^{24}$ although another in vitro study did not show problems in valve function with CSF protein contents of up to $9 \mathrm{~g} / \mathrm{L}$. ${ }^{6}$ Likewise, total RBC content and its clearing has been evaluated as a marker to reduce valve obstruction, but this parameter has not gained widespread use. ${ }^{9}$ Another study showed that total protein and RBC count does not affect the rate of shunt obstruction. ${ }^{23}$

Our study found that mean CSF lactate during Ommaya reservoir use was higher in the permanent shunt group; a value larger than $2.8 \mathrm{mg} / \mathrm{dl}$ had a positive predictive value of 0.94 for permanent shunt placement. We did not find comparable results in the literature. Although it is possible that this is a false-positive result, we believe it is necessary to validate this finding in further studies, because this could be a useful parameter to predict the early need for permanent shunt placement and avoid unnecessary additional Ommaya reservoir taps, which could potentially result in infection. ${ }^{32}$ A cutoff point in our study of $\geq 3 \mathrm{mg} /$ $\mathrm{dl}$ had a specificity of $90 \%$ and a value $\geq 3.5$ had a specificity of $100 \%$, that is, all those with a lactate value above this cutoff point required a permanent shunt. A possible explanation for this finding could be the consequence of oxidative stress caused by free iron; an increase in various cytokines has been observed in the CSF of posthemorrhagic infants. ${ }^{13,26}$ Lactate results as a metabolic byproduct of these mechanisms, which is increased if the CSF reabsorption pathways are deficient and/or suffer inflammatory damage, ${ }^{15}$ therefore resulting in a higher need for permanent shunt placement.

Nonrandomized trials have shown variable rates of infection and CSF leak between ventricular reservoirs and ventriculosubgaleal shunts. However, the need for repeated taps is larger in ventricular reservoirs, and the need for a permanent shunt is discretely higher in ventricular reservoirs as well, with this difference causing controversy and no large clinical trial to resolve it. Conversion rates to a permanent shunt vary between $65 \%$ and $95 \%$ among different authors. $14,28,30,31$

The rate of ventricular infections associated with temporizing measures has also been the subject of controversy. We excluded 5 patients from our study due to ventriculitis because management for this condition in our center consists of withdrawing the Ommaya reservoir and implanting an external ventricular drain, with the use of both intravenous and intrathecal antibiotics. All of these patients required multiple interventions that included a ventriculoperitoneal or ventriculoatrial shunt in addition to fenestration of cystic cavities. Consistent with other reports, there was a $100 \%$ shunt conversion rate in this group of patients. ${ }^{8}$ In addition, the objective of this study was to analyze the biochemical parameters of CSF as predictors of permanent shunt implantation, and the nature of the infectious process inexorably alters these biochemical parameters.

Most infections were due to gram-negative bacilli. Similar series have reported infection rates between $3 \%$ and $17 \%$, arguing that a higher number of taps (which is the case with an Ommaya reservoir) could be correlated with a higher risk of infection; ${ }^{32}$ however, no significant differences have been observed in comparison to ventriculosubgaleal shunts, despite its lower need for CSF taps, possible due to a low sample size, leaving this hypothesis still unclear. ${ }^{16,30,31}$

Infection of the permanent shunt at 6 months in our series happened in 2 cases (6.7\%), similarly to other studies. However, these rates are significantly lower than previously reported rates when lumbar taps were used as a temporizing measure for hydrocephalus, in which the rate approximated 35.4\%. ${ }^{4}$ Lumbar taps in our institution were only performed sparingly while placement of an Ommaya reservoir could be scheduled.

Shunt revision due to obstruction is higher in this group of patients than in other age groups, with reported obstruction rates between $45 \%$ to $84 \%, 5,24$ and revision-free shunt survival of $50 \%-70 \%$ in the first year of follow-up 24,30 and $36.2 \%$ at 3 years. ${ }^{16}$ In our series the revision rate in the first year was $43.3 \%$, without any clear biochemical or cellular CSF markers associated with a higher likelihood of obstruction. Time of Ommaya reservoir use was also not associated with obstruction, but greater age at the time of permanent shunt placement was correlated with obstruction; these findings should be verified in further studies.

Finally, we could not consistently measure total morbidity associated with permanent shunt placement. In a large cohort of patients that evaluated neural development in prematurity-associated posthemorrhagic hydrocephalus, patients who underwent permanent shunt placement had a higher long-term incidence of cerebral palsy and larger differences with worse scores on the Bayley II scale $^{20}$ compared to patients who did not require a permanent shunt. ${ }^{1}$

\section{Limitations of the Study}

The main limitation of this study is its retrospective nature and its low statistical power associated with the limited number of cases in the analysis, despite having data spanning several years. The other important limitation is the subjectivity of clinical variables and the lack of an interinstitutional management protocol for this condition, which hinders homogeneity and comparison with other studies. We believe that the findings in this study should be considered in future multicenter and prospective studies.

\section{Conclusions}

Management of GMH/IVH-associated hydrocephalus requires temporal shunting of CSF. A large percentage of these patients will require placement of a permanent shunt. Our study showed that risk factors associated with a significantly elevated risk of requiring conversion to a permanent shunt include greater than $10 \mathrm{ml} / \mathrm{kg}$ CSF extraction requirements, greater than $2.8 \mathrm{mg} / \mathrm{dl} \mathrm{CSF}$ lactate levels, and absence of symptomatic PDA. However, these results should be corroborated in future studies.

\section{References}

1. Adams-Chapman I, Hansen NI, Stoll BJ, Higgins R: Neurodevelopmental outcome of extremely low birth weight infants with posthemorrhagic hydrocephalus requiring shunt insertion. Pediatrics 121:e1167-e1177, 2008 
2. Anwar M, Kadam S, Hiatt IM, Hegyi T: Serial lumbar punctures in prevention of post-hemorrhagic hydrocephalus in preterm infants. J Pediatr 107:446-450, 1985

3. Badhiwala JH, Hong CJ, Nassiri F, Hong BY, Riva-Cambrin J, Kulkarni AV: Treatment of posthemorrhagic ventricular dilation in preterm infants: a systematic review and metaanalysis of outcomes and complications. J Neurosurg Pediatr 16:545-555, 2015

4. Behjati S, Emami-Naeini P, Nejat F, El Khashab M: Incidence of hydrocephalus and the need to ventriculoperitoneal shunting in premature infants with intraventricular hemorrhage: risk factors and outcome. Childs Nerv Syst 27:985989, 2011

5. Bir SC, Konar S, Maiti TK, Kalakoti P, Bollam P, Nanda A: Outcome of ventriculoperitoneal shunt and predictors of shunt revision in infants with posthemorrhagic hydrocephalus. Childs Nerv Syst 32:1405-1414, 2016

6. Brydon HL, Bayston R, Hayward R, Harkness W: The effect of protein and blood cells on the flow-pressure characteristics of shunts. Neurosurgery 38:498-505, 1996

7. Christian EA, Melamed EF, Peck E, Krieger MD, McComb JG: Surgical management of hydrocephalus secondary to intraventricular hemorrhage in the preterm infant. J Neurosurg Pediatr 17:278-284, 2016

8. Chu JK, Sarda S, Falkenstrom K, Boydston W, Chern JJ: Ventricular access device infection rate: a retrospective study and review of the literature. Childs Nerv Syst 30:1663-1670, 2014

9. Columbano L, Lüdemann WO, Stieglitz LH, Samii M: Repetitive cerebrospinal fluid flushing in a preterm newborn with posthaemorrhagic hydrocephalus. Technical note and review of literature. Clin Neurol Neurosurg 114:691-695, 2012

10. Davis P, Turner-Gomes S, Cunningham K, Way C, Roberts $\mathrm{R}$, Schmidt B: Precision and accuracy of clinical and radiological signs in premature infants at risk of patent ductus arteriosus. Arch Pediatr Adolesc Med 149:1136-1141, 1995

11. du Plessis AJ: The role of systemic hemodynamic disturbances in prematurity-related brain injury. J Child Neurol 24:1127-1140, 2009

12. Fountain DM, Chari A, Allen D, James G: Comparison of the use of ventricular access devices and ventriculosubgaleal shunts in posthaemorrhagic hydrocephalus: systematic review and meta-analysis. Childs Nerv Syst 32:259-267, 2016

13. Heep A, Stoffel-Wagner B, Bartmann P, Benseler S, Schaller $\mathrm{C}$, Groneck P, et al: Vascular endothelial growth factor and transforming growth factor- $\beta 1$ are highly expressed in the cerebrospinal fluid of premature infants with posthemorrhagic hydrocephalus. Pediatr Res 56:768-774, 2004

14. Lam HP, Heilman CB: Ventricular access device versus ventriculosubgaleal shunt in post hemorrhagic hydrocephalus associated with prematurity. J Matern Fetal Neonatal Med 22:1097-1101, 2009

15. Levene MI: Measurement of the growth of the lateral ventricles in preterm infants with real-time ultrasound. Arch Dis Child 56:900-904, 1981

16. Limbrick DD Jr, Mathur A, Johnston JM, Munro R, Sagar J, Inder T, et al: Neurosurgical treatment of progressive posthemorrhagic ventricular dilation in preterm infants: a 10-year single-institution study. J Neurosurg Pediatr 6:224-230, 2010

17. Maunu J, Lehtonen L, Lapinleimu H, Matomäki J, Munck $\mathrm{P}$, Rikalainen $\mathrm{H}$, et al: Ventricular dilatation in relation to outcome at 2 years of age in very preterm infants: a prospective Finnish cohort study. Dev Med Child Neurol 53:48-54, 2011

18. Mazzola CA, Choudhri AF, Auguste KI, Limbrick DD Jr, Rogido M, Mitchell L, et al: Pediatric hydrocephalus: systematic literature review and evidence-based guidelines. Part 2:
Management of posthemorrhagic hydrocephalus in premature infants. J Neurosurg Pediatr 14 (Suppl 1):8-23, 2014

19. Murphy BP, Inder TE, Rooks V, Taylor GA, Anderson NJ, Mogridge N, et al: Posthaemorrhagic ventricular dilatation in the premature infant: natural history and predictors of outcome. Arch Dis Child Fetal Neonatal Ed 87:F37-F41, 2002

20. Nellis L, Gridley BE: Review of the Bayley Scales of Infant Development-second edition. J Sch Psychol 32:201-209, 1994

21. Papile LA, Burstein J, Burstein R, Koffler H: Incidence and evolution of subependymal and intraventricular hemorrhage: a study of infants with birth weights less than 1,500 gm. J Pediatr 92:529-534, 1978

22. Papile LA, Munsick-Bruno G, Schaefer A: Relationship of cerebral intraventricular hemorrhage and early childhood neurologic handicaps. J Pediatr 103:273-277, 1983

23. Rammos S, Klopfenstein J, Augspurger L, Wang H, Wagenbach A, Poston J, et al: Conversion of external ventricular drains to ventriculoperitoneal shunts after aneurysmal subarachnoid hemorrhage: effects of site and protein/red blood cell counts on shunt infection and malfunction. J Neurosurg 109:1001-1004, 2008 (Erratum in J Neurosurg 110:196, 2009)

24. Reinprecht A, Dietrich W, Berger A, Bavinzski G, Weninger $\mathrm{M}$, Czech T: Posthemorrhagic hydrocephalus in preterm infants: long-term follow-up and shunt-related complications. Childs Nerv Syst 17:663-669, 2001

25. Riva-Cambrin J, Shannon CN, Holubkov R, Whitehead WE, Kulkarni AV, Drake J, et al: Center effect and other factors influencing temporization and shunting of cerebrospinal fluid in preterm infants with intraventricular hemorrhage. J Neurosurg Pediatr 9:473-481, 2012

26. Savman K, Nilsson UA, Blennow M, Kjellmer I, Whitelaw A: Non-protein-bound iron is elevated in cerebrospinal fluid from preterm infants with posthemorrhagic ventricular dilatation. Pediatr Res 49:208-212, 2001

27. Taylor AG, Peter JC: Advantages of delayed VP shunting in post-haemorrhagic hydrocephalus seen in low-birth-weight infants. Childs Nerv Syst 17:328-333, 2001

28. Tubbs RS, Banks JT, Soleau S, Smyth MD, Wellons JC III, Blount JP, et al: Complications of ventriculosubgaleal shunts in infants and children. Childs Nerv Syst 21:48-51, 2005

29. Vinchon M, Lapeyre F, Duquennoy C, Dhellemmes P: Early treatment of posthemorrhagic hydrocephalus in low-birthweight infants with valveless ventriculoperitoneal shunts. Pediatr Neurosurg 35:299-304, 2001

30. Wang JY, Amin AG, Jallo GI, Ahn ES: Ventricular reservoir versus ventriculosubgaleal shunt for posthemorrhagic hydrocephalus in preterm infants: infection risks and ventriculoperitoneal shunt rate. J Neurosurg Pediatr 14:447-454, 2014

31. Wellons JC III, Shannon CN, Holubkov R, Riva-Cambrin J, Kulkarni AV, Limbrick DD Jr, et al: Shunting outcomes in posthemorrhagic hydrocephalus: results of a Hydrocephalus Clinical Research Network prospective cohort study. J Neurosurg Pediatr 20:19-29, 2017

32. Whitelaw A: Repeated lumbar or ventricular punctures in newborns with intraventricular hemorrhage. Cochrane Database Syst Rev (1):CD000216, 2001

33. Whitelaw A, Aquilina K: Management of posthaemorrhagic ventricular dilatation. Arch Dis Child Fetal Neonatal Ed 97:F229-F233, 2012

34. Whitelaw A, Lee-Kelland R: Repeated lumbar or ventricular punctures in newborns with intraventricular haemorrhage. Cochrane Database Syst Rev 4:CD000216, 2017

\section{Disclosures}

The authors report no conflict of interest concerning the materi- 
als or methods used in this study or the findings specified in this paper.

\section{Author Contributions}

Conception and design: Palpan Flores, Saceda Gutiérrez, Sierra Tamayo, Carceller Benito. Acquisition of data: Palpan Flores, Saceda Gutiérrez, Sierra Tamayo. Analysis and interpretation of data: all authors. Drafting the article: Palpan Flores, Saceda Gutiérrez, Sierra Tamayo, Carceller Benito. Critically revising the article: Palpan Flores, Saceda Gutiérrez, Brin Reyes, Carceller Benito. Reviewed submitted version of manuscript: Palpan Flores,
Saceda Gutiérrez, Carceller Benito. Approved the final version of the manuscript on behalf of all authors: Palpan Flores. Statistical analysis: Palpan Flores. Administrative/technical/material support: Palpan Flores. Study supervision: Palpan Flores, Saceda Gutiérrez, Brin Reyes, Carceller Benito.

\section{Correspondence}

Alexis Palpan Flores: La Paz University Hospital, Madrid, Spain. alexispalpan@hotmail.com. 